\title{
Vasoplegic syndrome: A challenge to anaesthetic management
}

\author{
Amarjyoti Hazarika, Gyaninder P. Singh, Vishwas Malik', Parmod K. Bithal
}

\begin{abstract}
Perioperative hypotension is a well-recognized and relatively common problem during surgery. Vasoplegic syndrome is one such condition which is characterized by severe persistent hypotension with normal to high cardiac output and low systemic resistance. It is commonly seen in patients undergoing cardiac surgery on cardiopulmonary bypass. However, this syndrome has also been reported in off pump surgeries. Management of intraoperative hypotension may be challenging for an anaesthesiologist, if it does not respond or poorly respond to conventional therapy. We report the management of a hypertensive patient posted for spine surgery in prone position, who developed severe hypotension under anaesthesia refractory to treatment.
\end{abstract}

Key words: Anaesthesia, angiotensin converting enzyme inhibitor, refractory hypotension, vasoplegic syndrome

\section{INTRODUCTION}

Perioperative hypotension in prone position is a challenge to anaesthesiologists and more so if this hypotension is complicated by non responsiveness to conventional therapy. This non-responsiveness may be due to vasoplegic syndrome. We cite here a case report of probable vasoplegic syndrome in prone position.

\section{CASE REPORT}

A 52-year-old male patient weighing $70 \mathrm{Kg}$, diagnosed with D9-D11 ligamentum flavum hypertrophy with canal stenosis was posted for laminectomy in prone position. He was a known hypertensive and was on antihypertensive drugs (ramipril $2.5 \mathrm{mg}$ and hydrochlorothiazide $12.5 \mathrm{mg}$ ) for last 6 months. However, during pre-anaesthetic evaluation his blood pressure (BP) readings were high and so the cardiologist was consulted to review the

\begin{tabular}{|l|l|}
\hline \multicolumn{2}{|c|}{ Access this article online } \\
\hline Quick Response Code: & Website: \\
\hline & www.jnaccjournal.org \\
\cline { 2 - 2 } & \\
\hline
\end{tabular}

antihypertensive medicines. On cardiologist's advice the previous drugs were discontinued and amlodipine $5 \mathrm{mg}$ OD was added. The patient continued amlodipine for 9 days before his scheduled surgery and his BP was controlled. There was no history of syncope. On examination he had weakness in both lower limbs and was able to walk with support.

In the operating room, routine standard ASA monitoring was started. Anaesthesia was induced with fentanyl $2 \mu \mathrm{g} / \mathrm{kg}$ and propofol $150 \mathrm{mg}$ in titrated doses. Tracheal intubation was facilitated using rocuronium $1 \mathrm{mg} / \mathrm{kg}$. Following induction, right radial artery was cannulated for invasive BP monitoring. About 20 minutes after induction of anaesthesia, before turning the patient prone for surgery, sudden drop in BP was noticed. The mean arterial pressure (MAP) decreased from 85-47 mmHg. A rapid fluid bolus of 1 Liter normal saline was administered along with intermittent boluses of $5 \mathrm{mg}$ mephentermine (total $30 \mathrm{mg}$ ), but no rise in BP was seen. Phenylephrine was then given as intermittent bolus of 100-200 $\mu \mathrm{g}$ (total $1 \mathrm{mg}$ ) but again with no sustain response. However, the MAP never decreased below $45 \mathrm{mmHg}$ and there was no change in the electrocardiogram (ECG) trace on the monitor. An arterial blood gas analysis was performed which was normal with no sign of tissue hypoperfusion. After discussion with the surgery team, it was decided to

Departments of Neuroanaesthesiology, and ${ }^{1}$ Cardiac Anaesthesiology, All India Institute of Medical Sciences, New Delhi, India

Address for correspondence:

Dr. Gyaninder Pal Singh, Department of Neuroanaesthesiology, Room No. 711, $7^{\text {th }}$ Floor, Neurosciences Centre, All India Institute of Medical

Sciences, New Delhi - 110 029, India. E-mail: drsingh_gp@yahoo.co.in 
postpone the surgery and to evaluate the patient before taking up for surgery at a later date. However, BP began to rise once all the anaesthetic agents were discontinued and returned to the pre-induction levels as the patient was awakened.

Patient was re-investigated and opinion from cardiologist was sought. Cardiac evaluation including repeat 12 lead ECG and echocardiography was carried out but no significant cause could be detected. So the patient was again scheduled for surgery for the second time. This time special monitoring using, trans-esophageal echocardiography (TEE) and cardiac output monitor (Vigileo ${ }^{\mathrm{TM}} /$ FloTrac $^{\mathrm{TM}}$, Edwards Lifesciences, Irvine, CA, USA) was planned along with invasive BP and central venous pressure (CVP) monitoring. Induction of anaesthesia and tracheal intubation was smooth using titrated doses of thiopentone sodium $(300 \mathrm{mg})$, fentanyl $(2 \mathrm{mcg} / \mathrm{kg})$ and rocuronium $(1 \mathrm{mg} / \mathrm{kg})$. Anaesthesia was maintained with sevoflurane, oxygen and air. Right internal jugular vein and right radial artery was cannulated to monitor the CVP and arterial $\mathrm{BP}$ respectively. Also Vigileo ${ }^{\mathrm{TM}} /$ FloTrac $^{\mathrm{TM}}$ system to measure haemodynamic parameters (such as stroke volume (SV), cardiac output (CO), cardiac index (CI), systemic vascular resistance (SVR), stroke volume index (SVI), stroke volume variation (SVV)) was attached. About 30 minutes after the induction of anaesthesia, the same series of events repeated again and BP dropped from $106 / 70 \mathrm{mmHg}$ to $64 / 37 \mathrm{mmHg}$ (MAP from 84-44 mm Hg) over 3-4 minutes. The CVP was in the range of 10-12 $\mathrm{mmHg}$ in supine position. On TEE examination, ejection fraction (EF) was found to be $55 \%$ with SV around $90 \mathrm{ml}$ and CO around $4.2 \mathrm{~L} / \mathrm{min}$. The value of SVV was less than $7 \%$, however, the value of SVR obtained was 700 dynes.sec/ $\mathrm{cm}^{5}$ (normal range 800-1200 dynes.sec/ $\mathrm{cm}^{5}$ ). Hence, infusion nor-epinephrine was started after which BP started to rise and returned to normal. Surgery was carried out in prone position under the cover of nor-epinephrine infusion. SVR remained in the range of $850-1000$ dynes.sec/ $\mathrm{cm}^{5}$ during the procedure and rest of the intraoperative course was uneventful. At the end of the surgery, anaesthetic agents were stopped, neuromuscular blockade reversed and trachea was extubated. In the post operative period, BP remained in the normal range and the nor-epinephrine infusion was withdrawn. The patient was monitored in the ICU for 24 hours. Post surgery, the patient had no similar episode of hypotension or syncope and was finally discharged from the hospital after 3 days.

\section{DISCUSSION}

Hypotension in any clinical setting is worrisome more so, if it happens under anaesthesia. One of the causes of unexpected hypotension under anaesthesia is vasoplegic syndrome or shock. Though a definite definition of this syndrome is wanted, literature have defined it as a mean arterial pressure $<50 \mathrm{mmHg}$ with a cardiac index $>2.5 \mathrm{~L} / \mathrm{min} / \mathrm{m}^{2}$ and a low systemic vascular resistance despite adrenergic vasopressor administration..$^{[1]}$ Vasoplegic syndrome (VS) is not an uncommon finding in patients after they have undergone cardiopulmonary bypass (CPB). ${ }^{[2]}$ However, in our patient there was no such per-operative condition that could predispose to this syndrome.

During anaesthesia, rennin-angiotensin system (RAS) and the vasopressinergic system plays a pivotal role in maintaining BP. ${ }^{[3]}$ Angiostensin converting enzyme inhibitors (ACEI) and angiotensin receptor blockers (ARB) which blocks the RAS have been postulated to be a factor in increasing the incidence of VS ${ }^{[4,5]}$ especially in cardiac surgical patients where an increase upto $50 \%$ in incidence of VS is seen on taking these drugs. ${ }^{[6]}$ Our patient had a history of taking ACEI (ramipril). Data from literature, have advised to discontinue ACEIs/ARBs prior to anaesthesia to reduce the incidence of hypotension. ${ }^{[7]}$ However, a recent large retrospective trial from the Cleveland Clinic have suggested that the preoperative use of ACEIs (withholding ACEIs on the morning of surgery only) was not associated with an increase in perioperative vasopressor use, in-hospital complications or 30-day mortality.$^{[8]}$ Moreover, there are no specific guidelines regarding the timing of discontinuing ACEI before surgery. ${ }^{[9]}$ In our case, the drug was discontinued 9 days prior to surgery and was replaced by amlodipine. But literature on appropriate alternative agents in place of ACEIs for perioperative BP control is lacking.

Commonly, pressor catecholamines are administered to support the systemic arterial pressure in these cases. ${ }^{[10]}$ However, if this does not work, vasopressin can be an add on or alternative medication. In patient with shock, administration of vasopressin has resulted in increase in BP on average of 25-50 mmHg, when measures such as fluid replacement and catecholamine administration failed to do so. ${ }^{[11]}$ Clinical trials have demonstrated that patient on chronic ACEI/ARB medication under general anaesthesia, respond to exogenous vasopressin with an increase in BP and fewer hypotensive episodes. ${ }^{[3,12]}$ In our case, the patient's haemodynamic improved on nor-epinephrine infusion without the need for vasopressin. SVV value in our patient was less than $7 \%$ (values above $13 \%$ signifies hypovolemic status). ${ }^{[13]}$ This co-related well with CVP which was in a range of $10-12 \mathrm{mmHg}$ in supine position. However, the value of SVR obtained was 700 dynes.sec $/ \mathrm{cm}^{5}$ (normal range 800-1200 dynes.sec/ $\mathrm{cm}^{5}$ ). Hence, infusion nor-epinephrine was started to increase SVR and BP returned to normal. 
Another drug that can be helpful in this scenario is methylene blue (MB). MB counteracts nitric oxide and other nitro vasodilators effect on the endothelium and vascular smooth muscle. ${ }^{[14]}$ Studies have shown that use of MB has reduced incidence of mortality and morbidity. ${ }^{[15]}$ But due to numerous side effects like methhaemoglobinemia, hyperbilirubinemia, its use has been limited. In a recent study, it was found that administration of $\mathrm{MB}$ was an independent predictor of in-hospital mortality, compilation of morbidities, and hyperbilirubinemia in patients who received $\mathrm{MB}$ as treatment for vasoplegia during cardiac surgery with $\mathrm{CPB} \cdot{ }^{[16]}$

While many questions remain unanswered, it is agreed upon that refractory hypotension under general anaesthesia is a foreseen problem correlating with use of RAS antagonists. Suggestions are there to discontinue with the medication but guidelines regarding timing are lacking. If VS occur, pressor catecholamine still remains the first line drug with vasopressin analogue and $\mathrm{MB}$ as the second line therapy. Future studies are wanted to define the syndrome and to find out the cause for prevention and treatment of vasoplegic syndrome.

\section{REFERENCES}

1. Shanmugam G. Vasoplegic syndrome-the role of methylene blue. Eur J Cardiothorac Surg 2005;28:705-10.

2. Gomes WJ, Carvalho AC, Palma JH, Goncalves I Jr, Buffolo E. Vasoplegic syndrome: A new dilemma. J Thorac Cardiovasc Surg 1994;107:942-3.

3. Lange M, Van Aken $\mathrm{H}$, Westphal M Morelli A. Role of vasopressinergic $\mathrm{V} 1$ receptor agonists in the treatment of perioperative catecholamine-refractory arterial hypotension. Best Pract Res Clin Anaesthesiol 2008;22:369-81.

4. Mekonsto-Dessap A, Houel R, Soustelle C, Kirsch M, Thebert D, Loisance DY. Risk factors for post-cardiopulmonary bypass vasoplegia in patient with preserved left ventricular function. Ann Thorac Surg 2001;71:1428-32.

5. Meadows D, Edwards JD, Wilkins RG, Nightingale P. Reversal of intractable septic shock with norepinephrine therapy. Crit Care Med 1988;16:663-6.

6. Kwok ES, Howes D. Use of methylene blue in sepsis. A systematic review. J Intensive Care Med 2006;21:359-63.

7. Smith I, Jackson I. Beta-blockers, calcium channel blockers, angiotensin converting enzyme inhibitors and angiotensin receptor blockers: Should they be stopped or not before ambulatory anaesthesia? Curr Opin Anesthesiol 2010;23:687-90.

8. Turan A, You J, Shiba A, Kurz A, Saager L, Sessler DI. Angiotensin converting enzyme inhibitors are not associated with respiratory complications or mortality after noncardiac surgery. Anesth Analg 2012;114:552-60.

9. Wolf A, McGoldrick KE. Cardiovascular pharmacotherapeutic considerations in patients undergoing anesthesia. Cardiol Rev 2011;19:12-6.

10. Powers FM, Pifarre R, Thomas JX Jr. Ventricular dysfunction in norepinephrine-induced cardiomyopathy. Circ Shock 1994;43:122-9.

11. Morales D, Madigan J, Cullinane S, Chen J, Heath M, Oz M, et al. Reversal by vasopressin of intractable hypotension in the late phase of hemorrhagic shock. Circulation 1999;100:226-9.

12. Coriat P, Richer C, Douraki T, Gomez C, Hendricks K, GiudicelliJF, et al. Influence of chronic angiotensin-converting enzyme inhibition on anesthetic induction. Anesthesiology 1994;81:299-307.

13. Marik PE, Cavallazzi R, Vasu T, Hirani A. Dynamic changes in arterial waveform derived variables and fluid responsiveness in mechanically ventilated patients: A systematic review of the literature. Crit Care Med 2009;37:2642-7.

14. Oliveira Neto AM, Duarte NM, Vicente WV, Viaro F, Evora PR. Methylene blue: An effective treatment for contrast medium-induced anaphylaxis. Med Sci Monit 2003;9:CS102-6.

15. Fischer GW, Levin MA. Vasoplegia during cardiac surgery: Current concepts and management. Semin Thorac Cardiovasc Surg 2010;22:140-4.

16. Weiner MM, Lin HM, Danforth D, Rao S, Hosseinian L, Fischer GW. Methylene blue is associated with poor outcomes in vasoplegic shock. J Cardiothorac Vasc Anesth 2013;27:1233-8.

How to cite this article: Hazarika A, Singh GP, Malik V, Bithal PK. Vasoplegic syndrome: A challenge to anaesthetic management. J Neuroanaesthesiol Crit Care 2015;2:139-41.

Source of Support: Nil, Conflict of Interest: None declared. 